\title{
THE IMPORTANCE OF IRON ORE CHARACTERISATION AND DEM MODELLING IN MATERIALS HANDLING APPLICATIONS WITH A FOCUS ON WEAR ${ }^{\star}$
}

Tobias Krull Ken Williams ${ }^{2}$ Tim Donohue ${ }^{3}$ Dusan Ilic

\begin{abstract}
The characterisation of iron ore from a materials handling point of view is paramount in order to provide the best possible design for the desired application and maximise equipment uptime at the lowest possible capital and operational expenditure. Problematic issues in materials handling applications often arise in the iron ore industry due to the high density of the ore as well as the abrasive nature of the product. One of the key issues encountered during the handling of iron ore is excessive wear due to either impact or sliding abrasion. The applications and equipment typically affected by accelerated wear issues are mass flow hoppers, transfer chutes and conveyor belts. These wear issues often result in unplanned down times and loss in production which can lead to a considerable loss in revenue. This paper provides an overview of the best practises in the materials handling characterisation of iron ore and discusses available techniques for the modelling of iron ore in applications where accelerated wear is experienced. The application is illustrated through a number of industry relevant case studies for which engineering design work was undertaken to successfully reduce the wear rates of different materials handling equipment.
\end{abstract}

Keywords: Wear; Modelling; Characterization; Transfer chutes.

1 PhD, General Manager, TUNRA Bulk Solids, The University of Newcastle, NSW, Australia.

2 PhD, General Manager (Research), TUNRA Bulk Solids, The University of Newcastle, NSW, Australia.

$3 \quad$ PhD, Engineering Manager, TUNRA Bulk Solids, The University of Newcastle, NSW, Australia.

4 PhD, Senior Consulting Engineer, TUNRA Bulk Solids, The University of Newcastle, NSW, Australia.

\footnotetext{
* Technical contribution to the $44^{\text {th }}$ Ironmaking and Raw Materials Seminar, $15^{\text {rd }}$ Brazilian Symposium on Iron Ore and $2^{\text {nd }}$ Brazilian Symposium on Agglomeration of Iron Ore, September $15^{\text {th }}$ to $18^{\text {th }}$, 2014, Belo Horizonte, MG, Brazil.
} 


\section{INTRODUCTION}

In a practical sense, problems in materials handling applications are often cited in the iron ore industry as being responsible for equipment failure, downtime and lost revenue. Of particular significance are conveyor belt transfer points which covers both the chute liner materials as well as the conveyor belts. During the in-plant processing and handling of iron ores, most of the ore would have been transported by belt conveyors which are linked by transfer stations. As was highlighted in Donohue et al [1], it is not uncommon for a poorly designed transfer chute to last only 3-4 weeks before major maintenance is required. A poorly loaded belt may also only be in service for 18-24 months or less. Whilst the capital cost of replacing these items is always a consideration, the lost revenue from the associated downtime often significantly outweighs those costs.

The high density of iron ore as well as the abrasive nature of the final product are the key contributors to the wear of materials handling components. The characterization of iron ore from a materials handling point of view is therefore essential in order to provide the best possible design for the desired application and maximise equipment uptime at the lowest possible capital and operational expenditure.

The main focus of this paper is to present the findings from a comprehensive wear analysis via case studies. Those case studies rely extensively on calibrated Discrete Element Modelling to visualise the flow of the iron ore through the transfer chutes and to extract information that can be used for a detailed wear analysis.

\section{IRON ORE FLOW AND WEAR CHARACTERIZATION}

\subsection{Flow Properties Characterization}

For the design of chutes and hoppers from a flow point of view, the most important parameters are the surface wall friction and the internal friction (or bulk strength) of the iron ore. It has been shown by Roberts [2] that the wall friction depends on the interaction between the relevant properties of the iron ore and the lining surface with external factors such as the loading condition and environmental parameters having a significant influence.

\subsubsection{Bulk strength}

During the flow of iron ore in hoppers or high-throughput chutes with a wider range of particle sizes, the larger particles generally move bodily while the fines shear across themselves. Therefore, the bulk strength of the iron ore material and the associated risk of flow stoppages is dependent on the strength of the fines component. As a consequence, the strength of an iron ore is generally assessed on the fines size fraction despite containing larger size particles in parts of the process. It is imperative to undertake bulk strength testing in a direct shear testing machine which is equipped with a shear cell of circular cross section as shown schematically in Figure 1 . The normal load is applied to the cell by means of a vertical loading system and the shearing action is provided by means of an electro-mechanically driven loading stem which moves horizontally at a rate of $2.5 \mathrm{~mm} / \mathrm{min}$. The shear force is measured with a strain gauge load cell.

\footnotetext{
* Technical contribution to the $44^{\text {th }}$ Ironmaking and Raw Materials Seminar, $15^{\text {rd }}$ Brazilian Symposium on Iron Ore and $2^{\text {nd }}$ Brazilian Symposium on Agglomeration of Iron Ore, September $15^{\text {th }}$ to $18^{\text {th }}$, 2014, Belo Horizonte, MG, Brazil.
} 


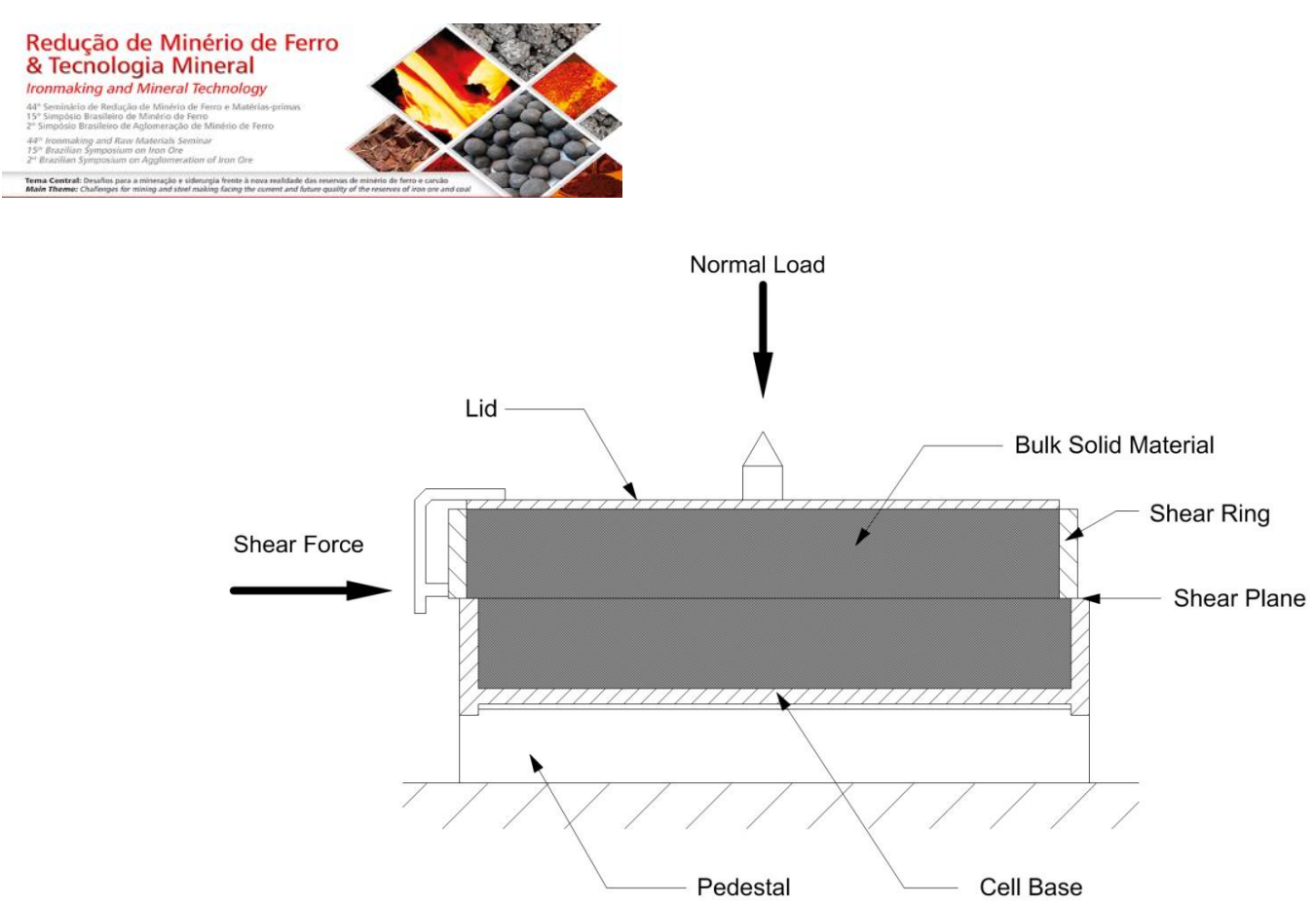

Figure 1. Direct shear test cell.

A more concise description of this testing technique is given in Roberts [3]. In the case of hopper designs, the effect of undisturbed storage time on consolidation should also be investigated using a time consolidation bench in conjunction with the shear tester given that many iron ores gain cohesive strength when left undisturbed for a period of time, in particular in the presence of surface moisture and clays. The purpose of such test work is to determine the amount of strength gained at a range of consolidation stresses relevant to the equipment design after undisturbed storage to allow design parameters to be calculated for these conditions. Such analysis is required in order to correctly design any hopper, bin or stockpile handling iron ore where the ore may be at rest for a period in excess of a number of hours.

\subsubsection{Wall friction and adhesion}

Wall friction and adhesion are both critical parameters in the design of hoppers and transfer chutes. The correct selection of wall liner materials is very important to the reliability and cost of materials handling equipment in that wall liners with higher wall friction tend to demand steeper chute and hopper angles whereas wall liners with low wall friction angles can result in higher velocities which could contribute to higher wear both in the chute walls as well as on the receiving conveyor.

The wall friction test is performed using a similar apparatus previous shown in Figure 1, however with a sample of wall liner material in place of the cell base. The bulk material is then sheared across the wall liner material under reducing normal stress to generate a so called wall yield locus which can be translated into a wall friction angle. For cohesive iron ores, this wall friction angle decreases with an increase in normal pressure. It is very important to understand the normal pressures acting in a bulk handling installation as this can have a significant influence on the selection of the best wall liner. As a consequence, for very low normal pressures where the friction angle may be quite large, the bulk solid will fail by internal shear rather than by boundary shear, thus leaving a layer of material on the surface. Such behavior must be prevented especially in transfer chutes as it can lead to material build-up and subsequent blockages.

The nature of adhesion and cohesion is however quite complex, according to Roberts [2] a study of this subject would require a detailed understanding of the physics and chemistry of the iron ore and the material surface. It is well known that

\footnotetext{
* Technical contribution to the 44 Ironmaking and Raw Materials Seminar, $15^{\text {rd }}$ Brazilian Symposium on Iron Ore and $2^{\text {nd }}$ Brazilian Symposium on Agglomeration of Iron Ore, September $15^{\text {th }}$ to $18^{\text {th }}$, 2014, Belo Horizonte, MG, Brazil.
} 
adhesion generally increase as the wall surface becomes smoother and as the moisture content of the iron ore increases.

\subsection{Wear}

Aside from material flow as was discussed in the previous section, wear is another very common issue experienced in materials handling applications and often is a product of two different types of wear, being impact wear and abrasive wear. The amount of wear is influenced by the abrasive properties of the iron ore being handled, the moisture content of the ore, the properties of the actual wear liner material, the throughput as well as the loading conditions which are characterized by the angle and velocity of impact and sliding. The focus of the case studies presented in this report is on impact wear and abrasive wear which are introduced in the following sections.

\subsubsection{Impact wear}

Impact wear, or erosive wear, is due to a combination of plastic deformation and cutting wear. This type of wear often occurs in transfer chutes where impact angles are high. These are typically where the bulk solid first impacts the impact plate, and also in the region where the bulk solid is loaded onto the receiving belt. It is known that impact wear depends on both the bulk solid and the surface being impacted, and that different surfaces behave differently. Limited testing methods are currently available to measure solely impact wear of wear liners and conveyor belt surfaces relevant to transfer chute applications. However, some general knowledge exists in that hard and brittle surfaces have low resistance to impact wear at steep angles of impact in the order of $60^{\circ}-90^{\circ}$ whereas ductile materials exhibit greatest erosive wear at low angles of impact $\left(15^{\circ}-30^{\circ}\right)$.

\subsubsection{Abrasive wear}

Abrasive wear, or sliding or rubbing wear, occurs when a hard rough surface (in this case iron ore) slides across a softer surface (a wear liner). Abrasion occurs in storage bins and hoppers, particularly when mass flow conditions are present where sliding of the bulk solid occurs along the hopper and bin walls. Transfer chutes can also suffer from high abrasive wear, however compared to bins, chutes typically experience much lower consolidation pressures but elevated velocities. When incorrectly designed, abrasive wear can also be an issue during loading of the receiving conveyor belt due a difference in material stream velocity to the belt speed. The measurement of linear abrasion in isolation from impact wear can be achieved in a purpose-built circular bed wear tester which has previously been developed by TUNRA - see Wiche et al [4] which was subsequently developed into a large scale tester, being capable of measuring and comparing the abrasive wear resistance of four wear liners simultaneously. The benefit of such a system as shown schematically in Figure is that the iron ore remains stationary within the outer annulus as the annulus is rotating by a motor at the base of the device. The wear liner materials are positioned atop the iron ore sample and a constant vertical pressure is applied. During the rotation of the annulus, a fixed plough lifts material from the bottom of the annulus to the top to ensure that fresh iron ore is presented as the abrading medium.

\footnotetext{
* Technical contribution to the $44^{\text {th }}$ Ironmaking and Raw Materials Seminar, $15^{\text {rd }}$ Brazilian Symposium on Iron Ore and $2^{\text {nd }}$ Brazilian Symposium on Agglomeration of Iron Ore, September $15^{\text {th }}$ to $18^{\text {th }}$, 2014, Belo Horizonte, MG, Brazil.
} 


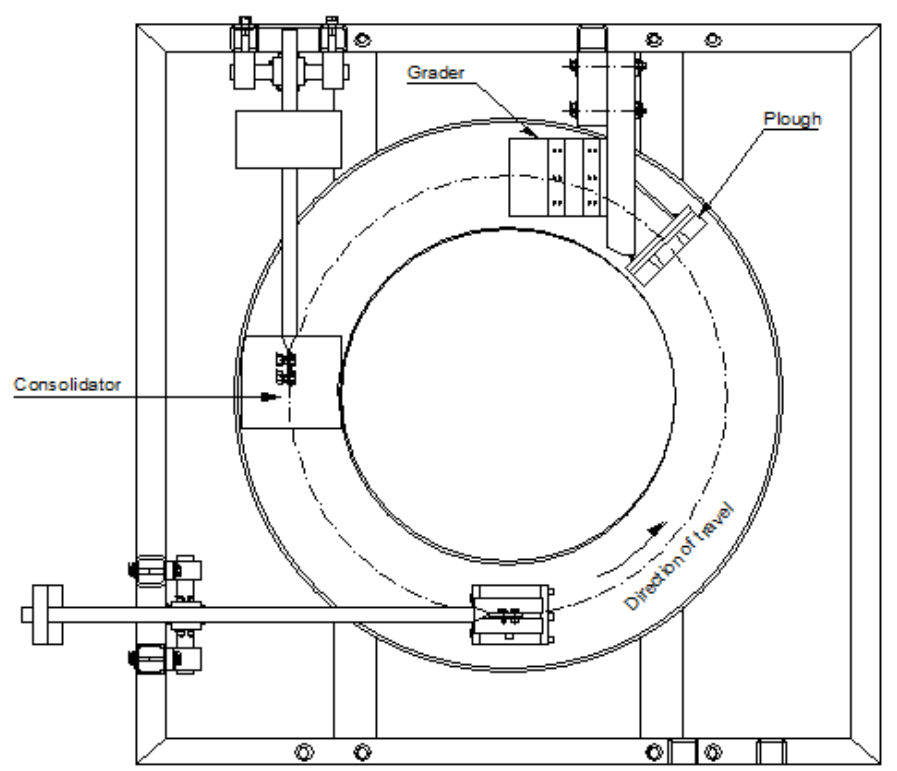

Figure 2. Circular Wear Tester Top View.

\section{DISCRETE ELEMENT MODELLING (DEM) OF BULK SOLIDS}

Discrete Element Modeling (DEM) is a technique which is increasingly employed in Australia and around the world to solve complex industrial problems in the space of mining and bulk material flow. Whereas most traditional analytical calculation approaches use incorporate a bulk or lump parameter analysis, those often cannot capture the effects between individual particles. The application of DEM in bulk solids handling has been covered extensively from a fundamental view point by Gröger and Katterfeld [5], in its basic principle it is used to model each individual (discrete) particle as a separate unit that is exposed to a range of forces similar to what is observed in reality. The motion of a particle is governed by the basic laws of motion and equations for translational and rotational motion are solved. The calculations performed in the DEM software alternate between the application of Newton's second law to the particles and a force-displacement law at the contacts. Newton's second law is then used to calculate the motion of each individual particle arising from the contact and body forces acting upon it, while the force-displacement law is used to update the contact forces arising from the relative motion at each contact. Such computational model can be very time consuming to complete with computational times ranging from many hours to weeks depending on the complexity of the design as well as the number and shape of particles in the system.

According to Donohue et al [1], DEM simulations are used increasingly for the simulation of material flow in transfer chutes. Because of the complex design of many transfer stations, there is an increasing need for the simulation of flow to fully understand particle movements and help optimizing the geometry for a given application. With the help of DEM it is not only possible to simulate and visualize the material flow but it also enables the analysis of forces acting on different parts of the transfer station including the physical chute and the receiving conveyor belt. Combining the analysis of forces and particle velocities it becomes possible to establish a wear profile, which is then used to optimize the design to minimize wear and increase the life of the asset, as shown in Katterfeld and Gröger [6].

\footnotetext{
* Technical contribution to the $44^{\text {th }}$ Ironmaking and Raw Materials Seminar, $15^{\text {rd }}$ Brazilian Symposium on Iron Ore and $2^{\text {nd }}$ Brazilian Symposium on Agglomeration of Iron Ore, September $15^{\text {th }}$ to $18^{\text {th }}$, 2014, Belo Horizonte, MG, Brazil.
} 
Due to high computational effort, idealizations of the simulation model are necessary to minimize calculation time, this often means that smaller particles are omitted and their parameters assigned to larger sized particles. However, those idealized simulation models require calibration of the simulation parameters to lead to realistic behavior. This is the reason why the calibration and selection of DEM parameters is one of the most critical steps in this modelling. The calibration provides the link between the "real" material properties as observed in reality and the simulation parameters. Calibration tests often characterize the particle-particle friction, particlewall friction, rolling friction as well as cohesion. The bench top testing as described in section 2 is widely used, however dynamic small scale flow tests are also used to supplement and provide an even more accurate link between the model environment and reality.

\section{DISCRETE ELEMENT MODELLING OUTCOMES}

\subsection{Introduction}

The DEM software used for the modelling presented in this paper is ROCKY, developed by Granular Dynamics International. This software uses a hysteresis linear spring model for the normal force interactions and an elastic-frictional force model in the tangential direction. Rolling resistance is implemented according to the type $\mathrm{C}$ model described in $\mathrm{Ai}$ et al. [7], while adhesive forces between particles and walls and cohesive forces between particles and particles are included through a constant force model. For the modeling work carried out and reported in this paper, the selection of parameters for DEM was based on TUNRA's extensive experience in modeling transfer chutes handling iron ore. Flow properties test work and calibration experiments had been performed to characterize iron ore fines which aids in calibrating the simulation parameters to improve modelling accuracy. As for the iron ore fines, frictional parameters were increased relative to the particle size to account for the absence of fines in the simulation as those cannot be modeled due to computational restrictions.

The authors are very active in this field of Discrete Element Modelling and have produced over 100 technical documents in this field. Reference is made to a paper by the same authors (Donohue et al [1]) with regards to following 2 case studies.

\subsection{Wear of an Impact Plate}

This actual case study focusses on an impact plate being part of an iron ore transfer chute lump ore at a throughput of $6500 \mathrm{tph}$. The impact plate was lined with ceramic tiles embedded in a rubber matrix, but suffered localized accelerated wear which meant it had to be replaced in under 2 months, this can be seen in Figure 3 showing how a hole had been worn through the plate from wear. Figure 4 (a) visualizes the flow through the impact plate as obtained from DEM simulation.

\footnotetext{
* Technical contribution to the 44 Ironmaking and Raw Materials Seminar, $15^{\text {rd }}$ Brazilian Symposium on Iron Ore and $2^{\text {nd }}$ Brazilian Symposium on Agglomeration of Iron Ore, September $15^{\text {th }}$ to $18^{\text {th }}$, 2014, Belo Horizonte, MG, Brazil.
} 


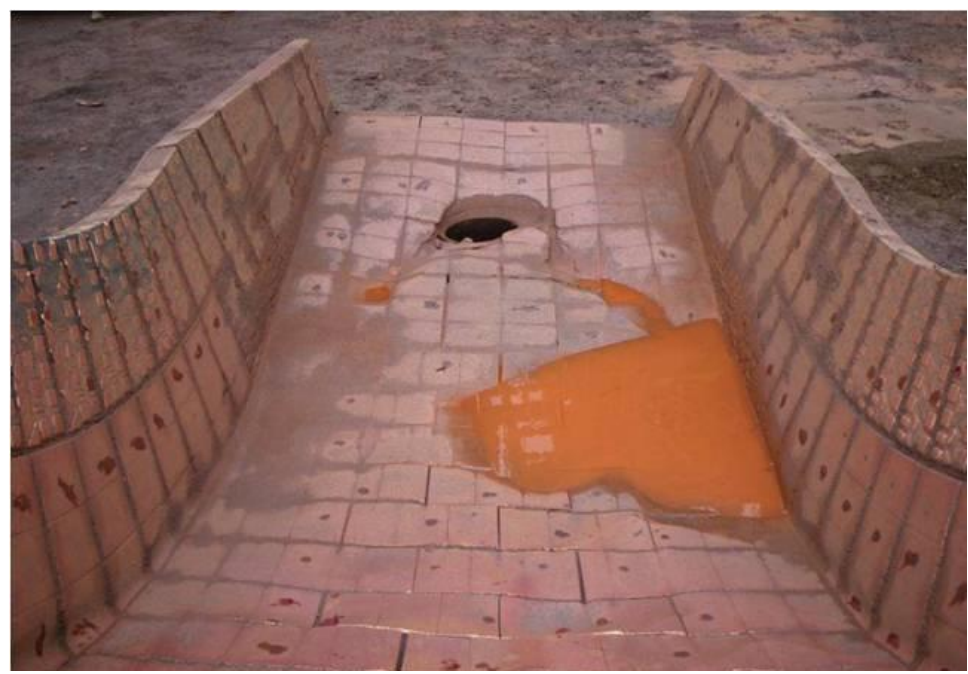

Figure 3. Impact plate showing wear.

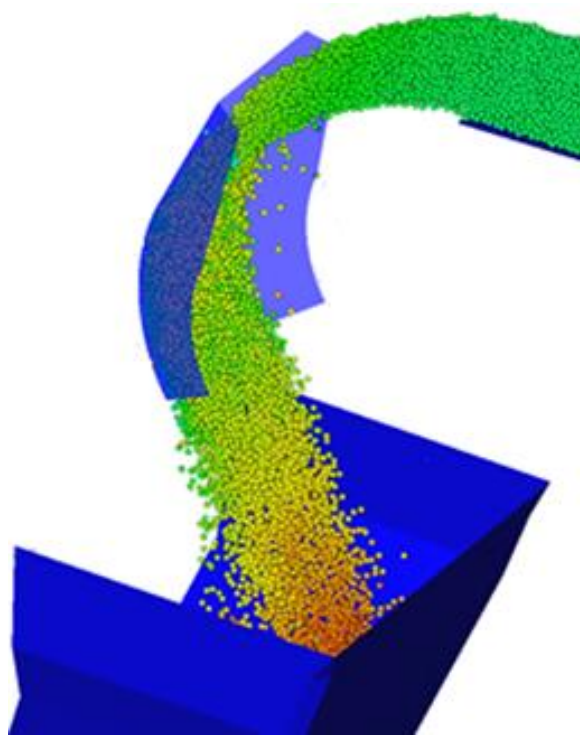

a)
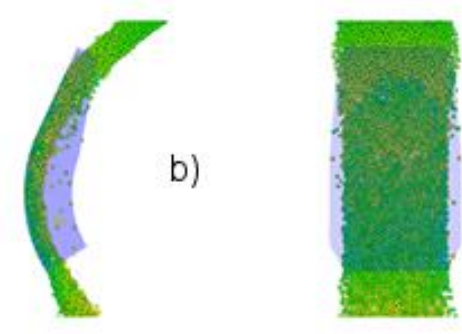

Figure 4. (a) View of flow through transfer chute (pulley and casing omitted for clarity) (b) Side and end elevation of existing impact plate (c) Side and end elevation of revised impact plate.

Preceding a complete re-design of the impact plate, computational modelling was also conducted on the existing design with the principle of re-positioning the chute to minimize the impact angle which is expected to be the main contributor to the accelerated wear. A whole series of DEM simulations was performed to evaluate the relative performance of the existing impact plate designs versus the re-positioned plates and also a revised impact plate design. This paper will focus only on the comparison between the existing and revised designs. Ultimately, the re-positioned impact plate designs were disregarded as they did not achieve the performance criteria of eliminating impact wear hot spots.

The basis of the revised design was to improve the wear performance of the existing design by not only reducing the angle at which the stream of iron ore impacts with the plate upon first contact, but also incorporating a combination of a converging section and gussets to more evenly distribute the impact pressures. Further images from the DEM simulations can be seen in Figure $4(b+c)$.

\footnotetext{
* Technical contribution to the $44^{\text {th }}$ Ironmaking and Raw Materials Seminar, $15^{\text {rd }}$ Brazilian Symposium on Iron Ore and $2^{\text {nd }}$ Brazilian Symposium on Agglomeration of Iron Ore, September $15^{\text {th }}$ to $18^{\text {th }}$, 2014, Belo Horizonte, MG, Brazil.
} 
Shown in Figure 5 are the wear contours obtained from DEM simulations which represent the impact intensity and shear (abrasion) intensity for the existing and redesigned plate profile. Those are calculated from DEM software outputs using a power calculation based on force and velocity averaged over a five second time frame when the chute was operating in steady state.

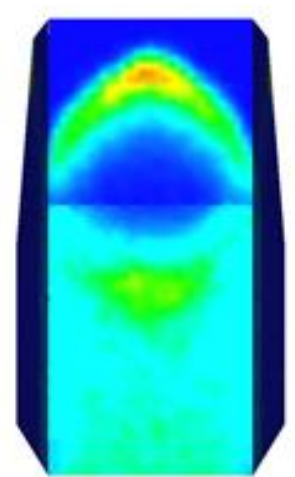

a)

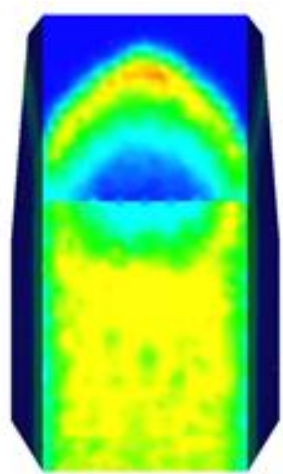

b)

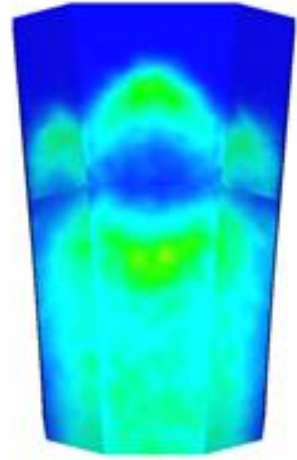

c)

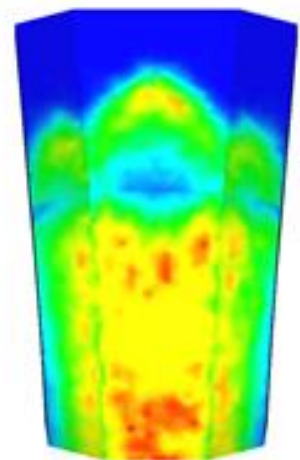

d)

Figure 5. (a) Existing - impact (b) Existing - abrasion (c) New - impact (d) New - abrasion.

It becomes evident that both the impact and shear intensity are lower in the top section of the revised design but are higher in abrasion (shear) around the central to lower section of the revised section. In reality, the actual wear experienced by the chute surface is due to a combination of impact wear and abrasive wear, however, the actual break-up of these two wear mechanisms is not easily quantified and will vary depending on the exact position on the chute surface.

For this particular application it was important to transfer the mode of wear from primarily impact to abrasion as it is well known that ceramic liners are much more resilient to abrasive wear compared to impact wear. From Figure 5 it is obvious that this had been achieved with the revised design being less exposed to impact wear which aided in significantly prolonging the life of the asset.

\subsection{Conveyor Belt Wear}

In this second case study from an iron ore processing plant, a transfer chute is presented where excessive wear was observed on the receiving belt. This accelerated wear occurred in the troughed regions of the belt and is illustrated in Figure 6 which shows thickness measurements taken across the stationary belt at regular increments over a 3 year period. A general view of the material flow through the chute as modeled using DEM can be seen in Figure 7. The analysis of the wear experienced on the receiving belt is presented in two separate sections, one focusing on impact wear and the other on abrasion caused by differential velocities.

\footnotetext{
* Technical contribution to the 44 Ironmaking and Raw Materials Seminar, $15^{\text {rd }}$ Brazilian Symposium on Iron Ore and $2^{\text {nd }}$ Brazilian Symposium on Agglomeration of Iron Ore, September $15^{\text {th }}$ to $18^{\text {th }}$, 2014, Belo Horizonte, MG, Brazil.
} 


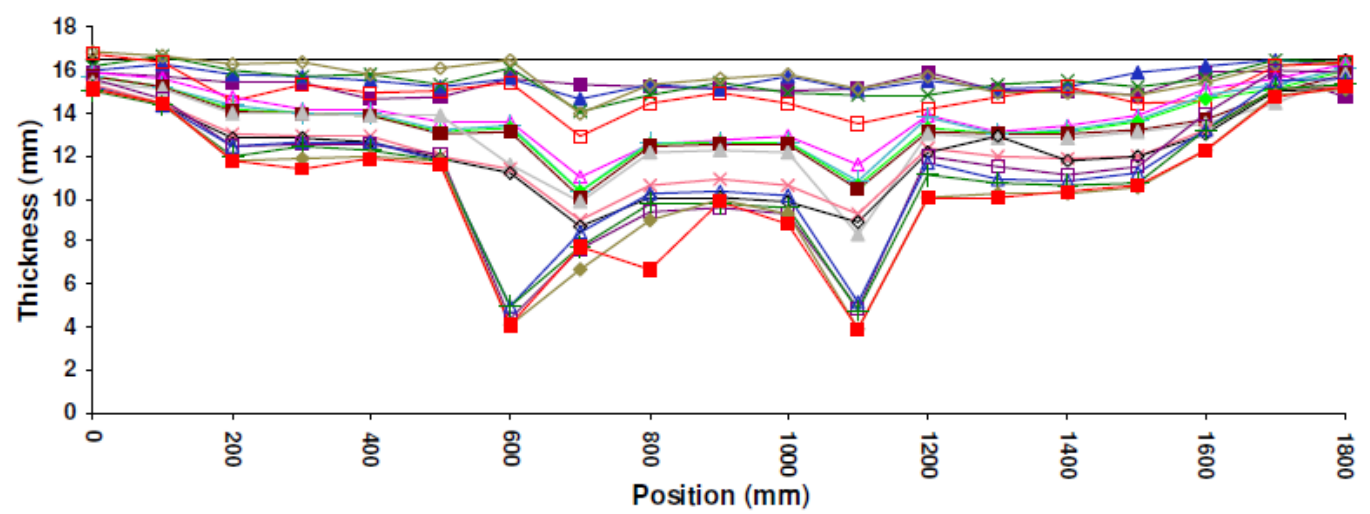

Figure 6. Belt Thickness Readings.

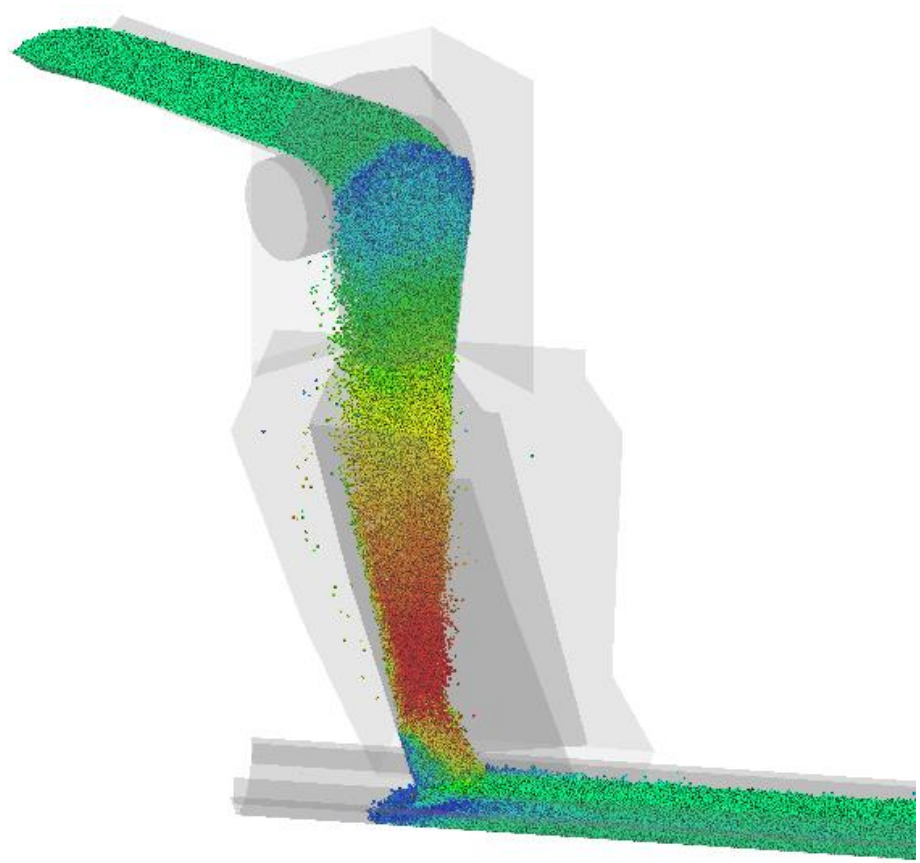

Figure 7. Transfer Chute Flow Visualization.

\subsubsection{Impact wear}

From the simulation outputs impact intensity contours were derived for the receiving belt, see Figure 8a. Furthermore, the values of impact intensity values were also discretized into regions across the belt, which allows to highlight regions of higher impact intensity as can be seen in Figure 8b. As is shown by both the contour graph and the plot of impact intensity the likely wear peaks in the middle of the belt. This is reflective of the majority of the stream discharging along the centerline of the chute. As was discussed previously, this impact intensity is calculated as a simple product of force and velocity, and makes no allowance for the impingement angle of the incoming material stream. An empirical relationship between angle of impingement and the rate of conveyor belt cover wear was presented previously by Pitcher [8]. Their analysis highlighted that the highest rate of wear on conveyors occurs in the impingement angle range of $20^{\circ}-40^{\circ}$.

* Technical contribution to the 44 Ironmaking and Raw Materials Seminar, 15 ${ }^{\text {td }}$ Brazilian Symposium on Iron Ore and $2^{\text {nd }}$ Brazilian Symposium on Agglomeration of Iron Ore, September $15^{\text {th }}$ to $18^{\text {th }}$, 2014, Belo Horizonte, MG, Brazil. 


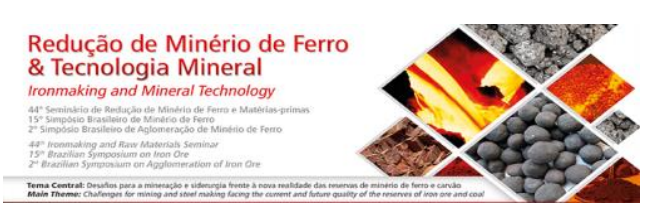

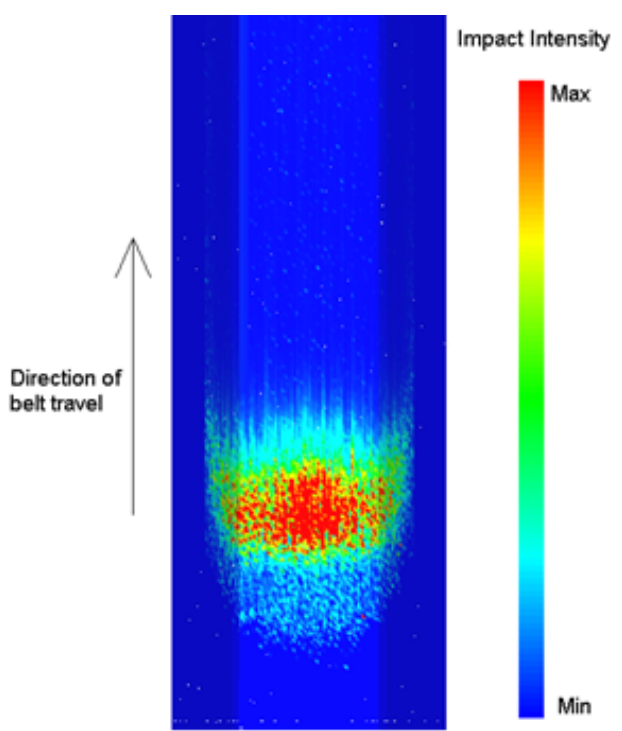

a)

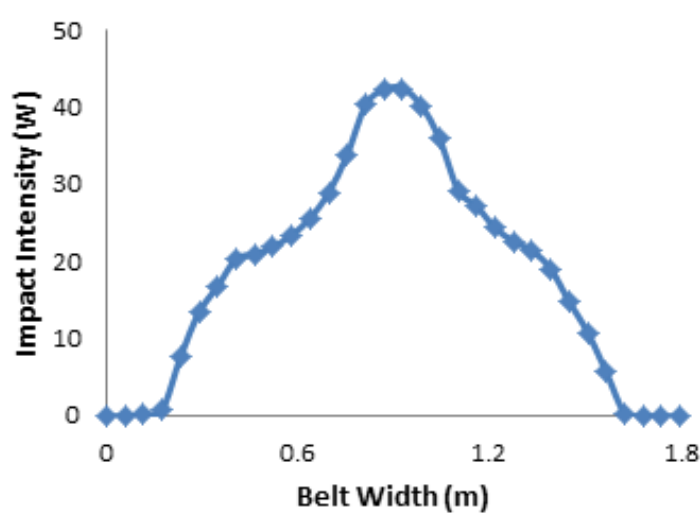

b)

Figure 8. (a) Impact intensity contours (b) Impact intensity across belt width.

With reference to a troughed conveyor belt, the material stream that impacts with the inclined sides of the troughed conveyor belt will have a lower impingement angle compared to the material stream impacting the horizontal section of the belt. This translates to a higher relative rate of wear for the inclined sides. By using the empirical data presented in Pitcher [8], the impact intensity results shown in Figure $8 \mathrm{~b}$ can be adjusted to incorporate an allowance for the impingement angle. This is possible by deriving from simulation the angle at which the material stream makes contact with the receiving belt across its width. These modified impact intensity results are shown in Figure 9 in relation to the receiving belt profile which is overlaid with this data. From this graph the modified wear rate is higher in the troughed regions of the belt, due largely to the lower impingement angles. For comparison purposes, the impingement angle in the curved troughed section varies between $35^{\circ}$ and $60^{\circ}$ compared to a value in the horizontal section of approximately $75^{\circ}$.

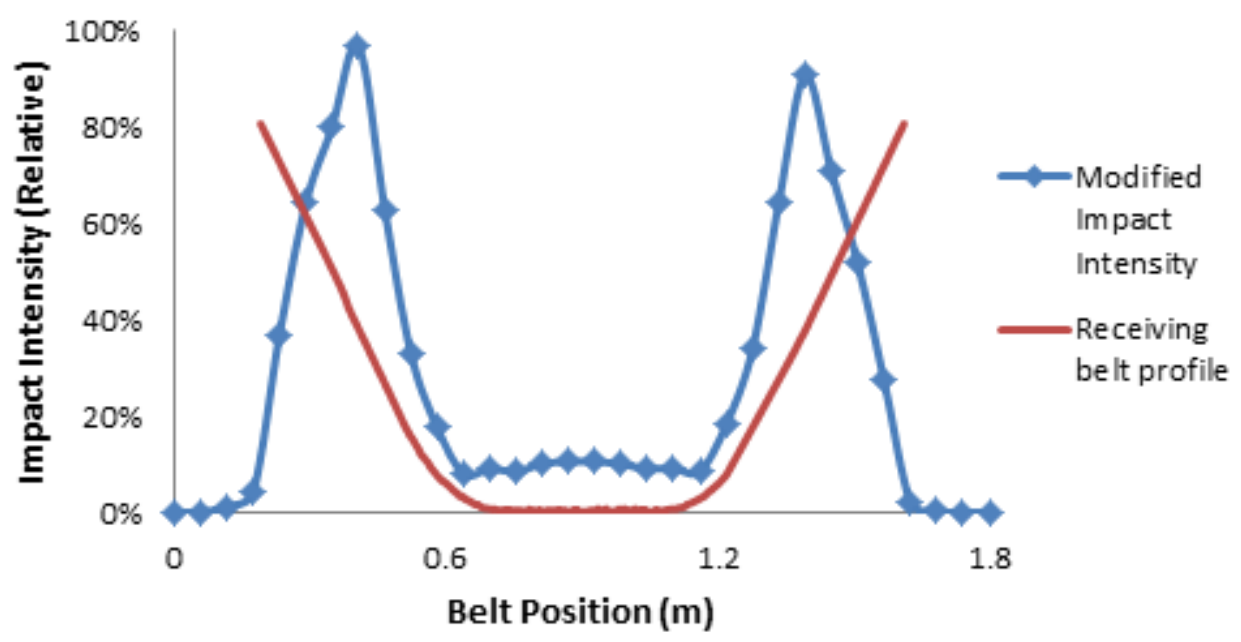

Figure 9. Adjusted impact velocities.

While the modification of the impact intensity data from the DEM simulation is based on an empirical relationship, it is clear that there will be regions of increased impact

\footnotetext{
* Technical contribution to the 44 Ironmaking and Raw Materials Seminar, $15^{\text {rd }}$ Brazilian Symposium on Iron Ore and $2^{\text {nd }}$ Brazilian Symposium on Agglomeration of Iron Ore, September $15^{\text {th }}$ to $18^{\text {th }}$, 2014, Belo Horizonte, MG, Brazil.
} 
wear, or cutting wear, in the troughed sections of the belt. The modified results presented in Figure 9 show a comparable trend to the site wear data shown in Figure 6.

\subsubsection{Abrasive wear}

With abrasive wear, it is important to consider the two main abrasion wear modes, known as two body abrasion and three body abrasion. In two body abrasion, the two surfaces in contact are constrained to move in two dimensions and as such wear occurs through the abrasive material on one surface sliding over the other surface. During three body abrasion, however, the abrasive material is trapped between two constraining surfaces and is free to roll as well as slide. While it is somewhat dependent on the particle size, Cenna et al [9] have shown that for particles abrading a rubber conveyor surface three body abrasion leads to higher wear rates compared to two body abrasion.

The outputs from the DEM simulation of this transfer chute allow for the rotational velocity of individual particles to be extracted so that an investigation of two and three body abrasion can be performed. Figure 10Figure presents results for the average rotational velocity magnitude and the relative translational velocity taken over a two second steady state period for all particles in direct contact with the belt surface. This graph also highlights that the relative translational velocity is equivalent to the belt speed at the loading point of about $3.8 \mathrm{~m} / \mathrm{s}$ which indicates the lack of velocity component in the direction of the belt travel. Also shown in this graph is the trend for the particles to accelerate towards the belt speed and the approximate horizontal distance this occurs in.

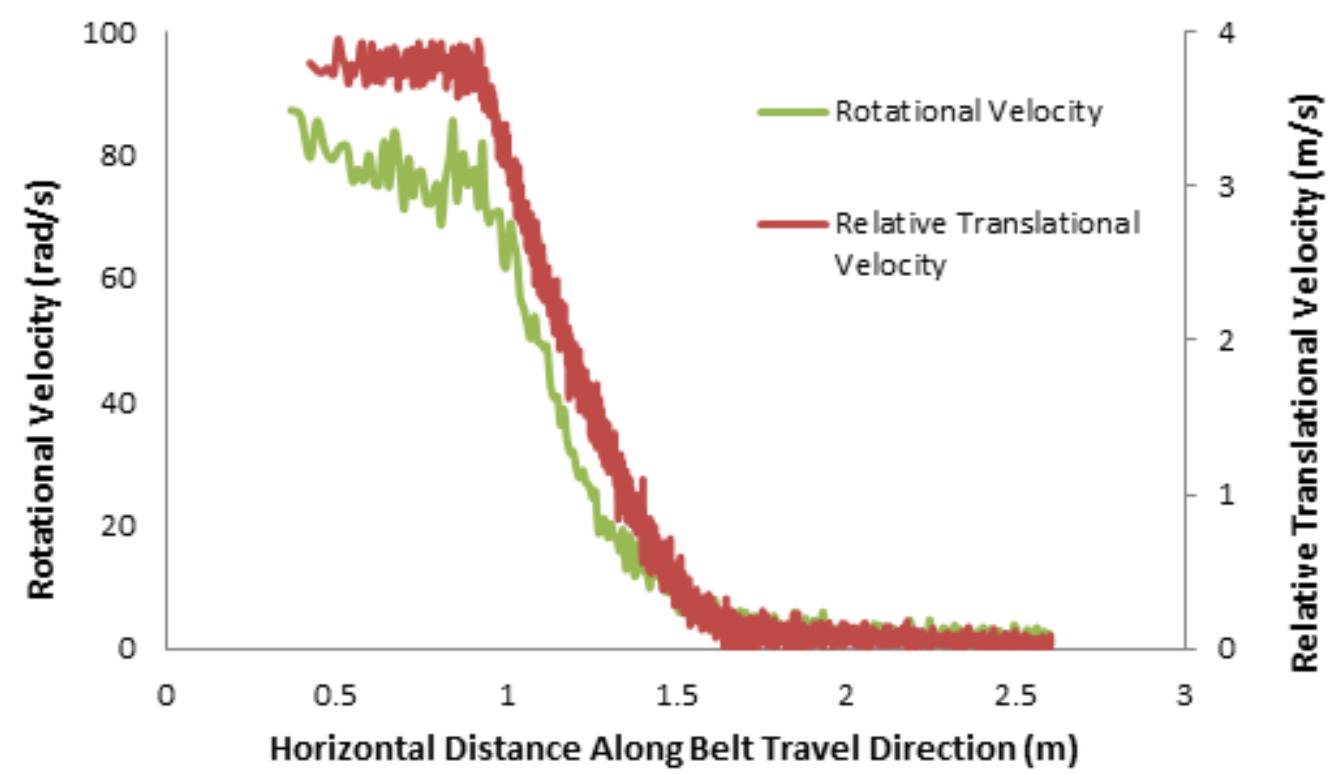

Figure 10. Rotational and relative translational velocities.

From the data shown in Figure 10, it can be concluded that there is a possibility for both two body and three body wear to occur. The average rotational velocity indicates that the predominant wear mechanism is three body wear. However, given this is an average rotational velocity there will still be individual particles with small to

\footnotetext{
* Technical contribution to the $44^{\text {th }}$ Ironmaking and Raw Materials Seminar, $15^{\text {rd }}$ Brazilian Symposium on Iron Ore and $2^{\text {nd }}$ Brazilian Symposium on Agglomeration of Iron Ore, September $15^{\text {th }}$ to $18^{\text {th }}$, 2014, Belo Horizonte, MG, Brazil.
} 
zero rotations. It can also be concluded that two body wear will also be observed given the very high relative translational velocity in the loading zone.

\section{CONCLUSIONS}

This paper highlights the importance for material characterization and computational modelling in order to accurately understand the wear behavior in bulk materials handling equipment. The correct understanding of bulk strength, wall friction, adhesion and wear properties is paramount in calibrating the correct simulation parameters which leads to modelling outcomes which closely reflect reality. This is of importance at the stage of equipment design in order to prevent design flaws which lead to accelerated wear, reduced life of assets and equipment downtime.

As is evidenced through the presented case studies, material characterization and computational modelling are equally relevant to the troubleshooting of existing assets. With the help of the tools presented in this report, it is possible to accurately re-engineer solutions to prevent accelerated wear and improve the life of expensive assets. It is now possible to not only identify zones of high wear prior to fully committing to a design but in case of existing installations, real site data can be used to calibrate the models and changes to the equipment can be made to improve overall efficiency and uptime.

\section{REFERENCES}

1 Donohue TJ, llic D, Krull T. Modelling of iron ore in materials handling applications with a focus on Wear. Iron Ore 2013 Conference, Perth, Australia, 2013.

2 Roberts AW. Chute design considerations for feeding and transfer. Research Paper, Centre for Bulk Solids and Particulate Technologies. The University of Newcastle, Australia, 1998.

3 Roberts AW. Basic principles of bulk solids storage, flow and handling. Research Paper, The Institute for Bulk Materials Handling Research, Newcastle, Australia 1993.

4 Wiche SJ, Keys S, Roberts A W. Abrasion wear tester for bulk solids handling applications, Wear, 2005; (258):251-257.

5 Gröger T, Katterfeld A. Application of the discrete element method in materials handling: Basics and calibration; Bulk Solids Handling, 2007; 27(1):17-23.

6 Katterfeld A, Gröger T. Simulation based wear prediction of transfer chutes. Proceedings Bulk Europe 2008 International Conference, 2008.

$7 \mathrm{Ai} \mathrm{J}$, Chen J, Rotter M, Ooi JY. Assessment of rolling resistance models in discrete element simulations, Powder Technology, 2011; (206):269-282.

8 Pitcher DM. Predicting the life of rubber covered conveyor belting. Proceedings of Beltcon 11, 2001.

9 Cenna AA, Allen S, Page NW, Dastoor P. A polyethylene-reinforced polymer composite abraded by bulk solids, Wear, 2001; (249):663-671.

* Technical contribution to the 44 Ironmaking and Raw Materials Seminar, $15^{\text {rd }}$ Brazilian Symposium on Iron Ore and $2^{\text {nd }}$ Brazilian Symposium on Agglomeration of Iron Ore, September $15^{\text {th }}$ to $18^{\text {th }}$, 2014, Belo Horizonte, MG, Brazil. 